\title{
Deformidades do Pé - conceitos básicos e orientações para o Médico de Família
}

Francisco Sant'Anna,* Manuel Cassiano Neves**

\section{RESUMO}

O pé da criança constitui uma das principais preocupações dos pais em relação ao futuro da criança. Os autores abordam, de forma resumida, as principais deformidades do pé da criança, bem como as suas indicações terapêuticas e fornecem indicações sobre as atitudes a tomar pelo médico de família ou pediatra.

Palavras-Chave: Pé; Criança; Deformidades; Pé Plano; Pé Boto

\section{INTRODUÇÃO}

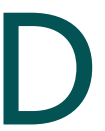
esde o nascimento e ao longo da infância, o desenvolvimento do pé tem constituído uma fonte de preocupação para os pais, pediatras e generalistas e uma causa comum de consulta em Ortopedia.

Embriologicamente, o pé desenvolve-se entre as $4 \mathrm{e}$ as 8 semanas de gestação e o seu crescimento termina antes do resto do corpo. Aos 18 meses de vida já atingiu cerca de metade do comprimento total, e até ao início da adolescência atinge o seu desenvolvimento completo. Este facto obriga a substituições frequentes de calçado, para acompanhar o crescimento rápido durante a infância. ${ }^{1}$

\section{A ARCADA PLANTAR}

O arco longitudinal do pé, a que habitualmente se chama arcada plantar, desenvolve-se com o crescimento, tornando-se mais evidente a partir dos dois anos, altura em que começa a desaparecer a gordura do pé do recém-nascido. $O$ pé plano infantil resulta da combinação de gordura subcutânea e da laxidão articular, predominantes na infância. Quando a criança apoia o pé, a arcada abate sob o peso e a gordura subcutânea, mais abundante na região plantar, apaga a visualização da arcada.

*Assistente Hospitalar Graduado em Cirurgia Pediátrica

Serviço de Ortopedia, Hospital Dona Estefânia, Lisboa, Portugal

\section{VARIABILIDADE NORMAL}

Radiologicamente, existe uma grande variabilidade da anatomia normal do pé. Há vários centros de ossificação acessórios (ossos: navicular, trigono, vesalianum, maleolar interno e maleolar externo), que são frequentemente confundidos com fracturas e que também podem originar queixas dolorosas. O estudo radiográfico do pé deverá ser efectuado em carga e, por vezes, também em incidência oblíqua. A comparação com o lado oposto é obrigatória e essencial, pois permite diferenciar as alterações do desenvolvimento, habitualmente bilaterais, das situações patológicas.

\section{DEFORMIDADES MAIS FREQUENTES}

Nas deformidades dos pés há que distinguir as deformidades congénitas das deformidades do desenvolvimento. Perante um recém-nascido com uma deformidade, é necessário perceber se se trata de uma deformidade postural, habitualmente flexível, ou de uma deformidade patológica, habitualmente rígida, pois o prognóstico é totalmente diferente. A deformidade postural tem tendência a regredir espontaneamente, sem tratamento ou com tratamento mínimo, enquanto uma deformidade rígida é uma doença que obriga a tratamentos continuados e, eventualmente, a cirurgia.

\section{Deformidades congénitas}

Metatarsus aductus ou varus. É a deformidade mais frequente do pé, com uma incidência de 1/1.000 nas- 
cimentos, sendo mais frequente na rapariga. Existem três tipos:

- Metatarsus aductus: é uma deformidade posicional frequente (relacionada com a posição intra-uterina), em que existe uma convexidade do bordo externo do pé, flexível e com evolução benigna para a cura espontânea, cerca do ano de idade. Está associado a doença displásica da anca.

- Metatarsus varus: é uma deformidade mais rara, rígida, em que os metatarsos se encontram voltados para dentro. Pode originar problemas com o uso de calçado e obriga a tratamento com gessos seriados, para correcção, seguidos de ortóteses para manutenção da correcção.

- Abdução do Halux (SearchingToe): é uma deformidade dinâmica, por hiperactividade do músculo abdutor do dedo. Evolui para a cura sem necessidade de tratamento.

\section{Pé boto (equinovaro)}

Esta entidade, mais frequente no sexo masculino, tem uma incidência de cerca de 1/1.000 nascimentos. Em $50 \%$ dos casos é bilateral.

Trata-se de uma deformidade complexa, com equinismo do retropé, varismo, supinação e cavum. É, por vezes, confundido com o metarsus varus, mas distingue-se deste pela existência do equinismo por retracção do tendão de Aquiles.

Existe um componente malformativo ósseo, com hipoplasia dos ossos do tarso, especialmente do astrágalo. Pode estar associado a outros problemas ortopédicos e a sua gravidade depende não só da deformidade em si, mas, sobretudo, da sua rigidez.

O facto de ser uma deformidade congénita, de base genética, condiciona a sua evolução; caracteriza-se, na idade adulta, por um pé de aspecto normal, mas, por vezes, ligeiramente mais pequeno e por uma atrofia dos músculos da perna.

O seu tratamento tem evoluído ao longo dos tempos. Actualmente, o tratamento de eleição consiste na aplicação de gessos seriados, associada a tenotomia do tendão de Aquiles, na altura do último gesso, conforme descrito por Ponseti. ${ }^{3}$ A taxa de recidiva é elevada, pelo que é fundamental a utilização de uma ortótese para dormir, que se mantém até aos 3-5 anos, dependendo da severidade da deformidade à nascença.

\section{Pé plano congénito}

Trata-se de uma deformidade de difícil diagnóstico à nascença, por ser rara e pouco perceptível, mas que, se não tratada, pode ter repercussões importantes na idade adulta.

O recém-nascido apresenta uma deformidade que se caracteriza pela forma convexa da planta do pé, tipo mata-borrão, notando-se o desaparecimento da arcada longitudinal interna e palpando-se, em seu lugar, uma tumefacção dura, que corresponde à cabeça do astrágalo (astrágalo vertical) (Figura 1).

É a forma mais grave de pé plano patológico e uma das mais difíceis de tratar. Está, muitas vezes, associada a outras malformações ortopédicas, como a displasia da anca, torticolis ou outras malfomações, nomeadamente do aparelho urinário.

$O$ aspecto radiográfico é típico na incidência de perfil, com a verticalização do astrágalo e a cabeça deste induzindo a convexidade da região plantar. A sua rigidez não permite resultados satisfatórios com o tratamento conservador com gessos e o tratamento cirúrgico deve ser encarado no primeiro ano de vida.

\section{Calcaneovalgus}

É uma deformidade posicional, que evolui espontaneamente para a cura, podendo estar associada à displasia da anca. Pode ser confundida com o astrágalo vertical congénito, diferenciando-se deste pela sua flexibilidade. Não requer tratamento.

\section{Deformidades do desenvolvimento Pé plano infantil}

Nesta entidade, a diminuição da altura ou abatimento da arcada plantar provoca um aumento da área de contacto do pé com o solo (Figuras 2, 3 e 4).

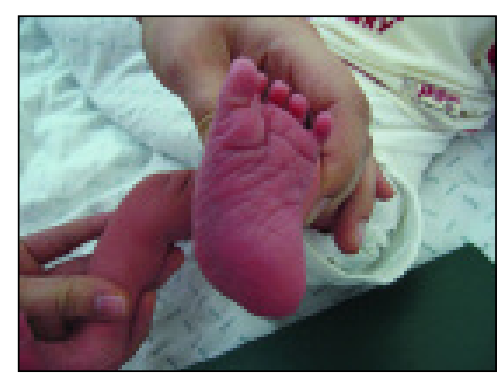

Figura 1. Pé Plano congénito 


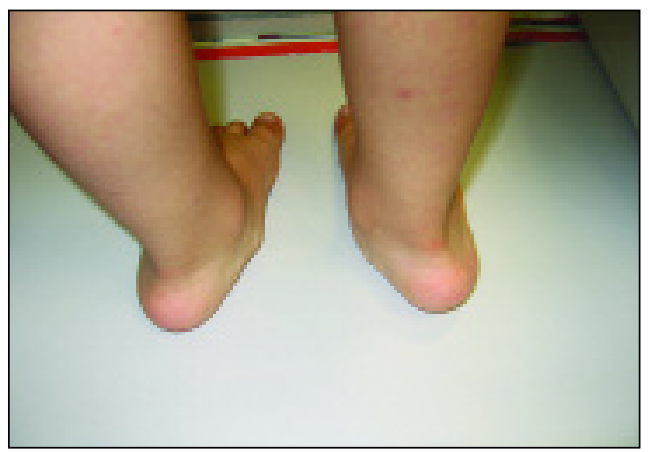

Figura 2. Pé plano laxo infantil

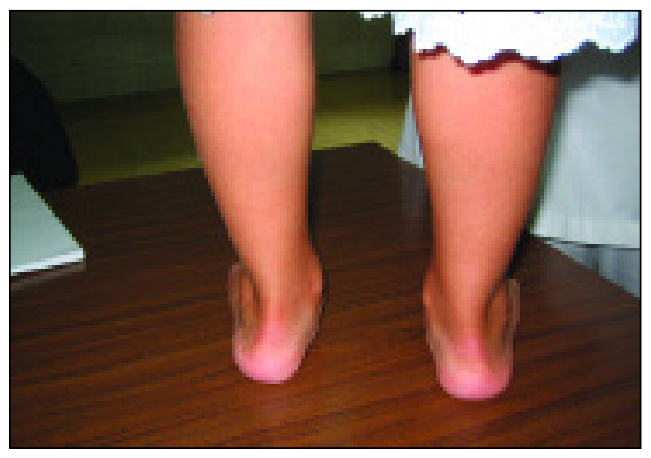

Figura 3. Pé plano laxo infantil

Existem dois tipos de pé plano: o fisiológico e o patológico. O primeiro (pé plano laxo infantil) é uma variante do normal, flexível e benigna. ${ }^{4}$ Pode ter uma incidência familiar e é muito frequente na primeira infância; a sua incidência diminui gradualmente, até cerca de 10 a 15\% nos adultos. Está associado a hiperlaxidão ligamentar e não necessita de tratamento. Ao contrário do que é comum acreditarmos, não beneficia com o uso de calçado correctivo, mas sim com a actividade desportiva e o uso de calçado flexível.

O pé plano patológico é mais rígido, provoca problemas e tem uma correcção difícil e complicada, podendo ter várias etiologias.

\section{Pé plano em $Z$ ou pé em serpentina}

É uma deformidade complexa, rara, com um valgismo do retropé, uma adução do antepé e abatimento da arcada plantar. Necessita tratamento complexo no fim do crescimento, com alongamentos tendinosos e osteotomias diversas.

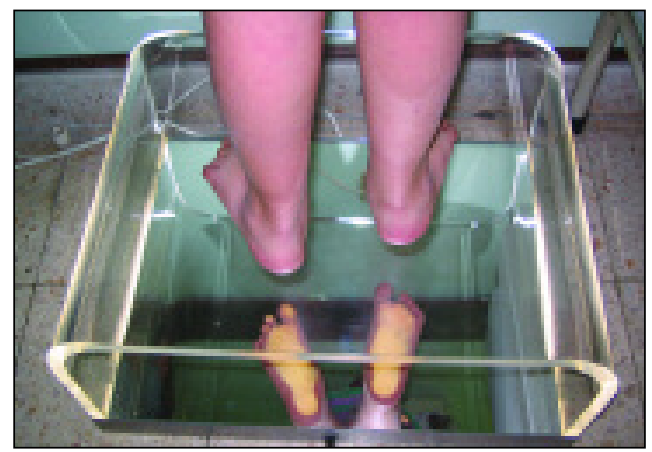

Figura 4. Pé plano - podoscópio

Notar o apoio total da planta do pé

\section{Pé plano com retracção do tendão de Aquiles}

A retracção do tendão de Aquiles provoca um desvio em valgo do calcâneo, com alterações do movimento normal do pé, provocando queixas dolorosas mais ou menos intensas. Na maioria das vezes, as queixas estão directamente relacionadas com os esforços e são referidas aos pés, mas, também, aos músculos das pernas. É frequentemente confundida com o pé plano flexível, que, no entanto, não tem esta retracção tendinosa. $\mathrm{O}$ tratamento é cirúrgico, cerca dos 6-8 anos de idade.

\section{Pé plano por fusão társica (barra társica)}

Trata-se de uma deformidade rígida e dolorosa, que se caracteriza por um pé plano, associado a uma espasticidade dos músculos peroneais e que, quando assintomática, pode passar despercebida.

Em termos anátomo-patológicos caracteriza-se pela presença de uma ponte entre os ossos do pé. Os tipos mais frequentes são a barra astrágalo-calcaneana e a calcâneo-escafoideia e podem ser constituídas por osso, cartilagem ou apenas por um tecido fibroso.

Manifesta-se, habitualmente, no início da adolescência, altura em que se inicia o último surto de crescimento do pé, como um pé plano rígido e doloroso. As barras ósseas originam sobrecargas nas articulações adjacentes, mas podem, por vezes, ser assintomáticas.

O tratamento pode ser mais ou menos complexo, consoante os casos e o resultado nem sempre é satisfatório, nomeadamente nas barras astrágalo-calcaneanas (mais difíceis de ressecar). ${ }^{5}$

\section{Pé plano neuromuscular}

É comum nos doentes com paralisia cerebral e é cau- 


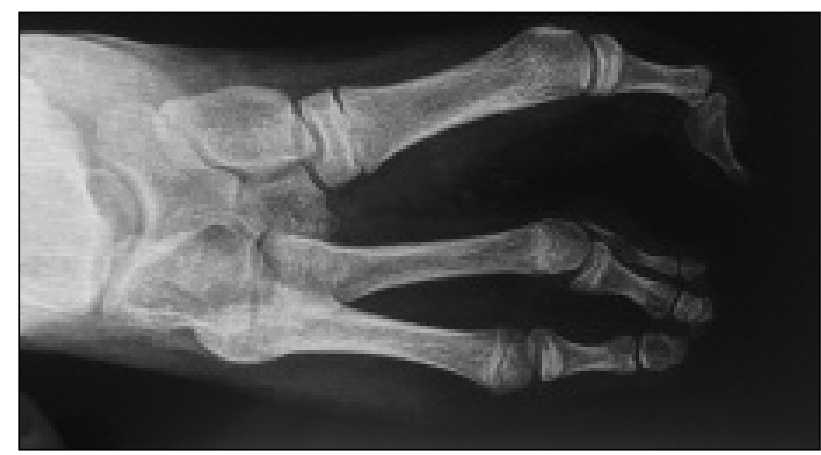

Figura 5. Pinça de Lagosta

sado pelo desequilíbrio muscular e pela espasticidade. A sua estabilização cirúrgica é requerida especialmente nos doentes com potencial de marcha.

\section{Pé cavo}

O aumento da arcada plantar, associado a varismo do retropé e dedos em garra são as características principais desta deformidade.

Existe uma forma fisiológica, com aumento moderado da arcada plantar, sem défices neurológicos associados e com incidência familiar. Pode dar origem a metatarsalgias e calosidades na adolescência, devendo ser referenciado à consulta de ortopedia quando sintomático.

O pé cavo congénito é raro e corresponde a uma deformidade posicional com correcção espontânea.

O pé calcaneocavo é mais frequente na poliomielite, no mielomeningocelo e como forma iatrogénica, em casos de alongamento excessivo do tendão de Aquiles.

O pé cavovaro é a forma mais frequente; acompanha-se de dedos em garra e deve-se a um desequilíbrio muscular de base neurológica ainda que às vezes não seja identificada a doença causal.

O tratamento, conservador ou cirúrgico, depende do tipo e gravidade da situação.

\section{DEFORMIDADES DOS DEDOS}

\section{Pinça de Lagosta (Lobster Claw deformity)}

Esta entidade, transmitida de forma autossómica dominante, é, geralmente, bilateral e pode envolver também as mãos (Figura 5).

Origina problemas no uso de calçado e o tratamento deve ser dirigido para o fim do crescimento.

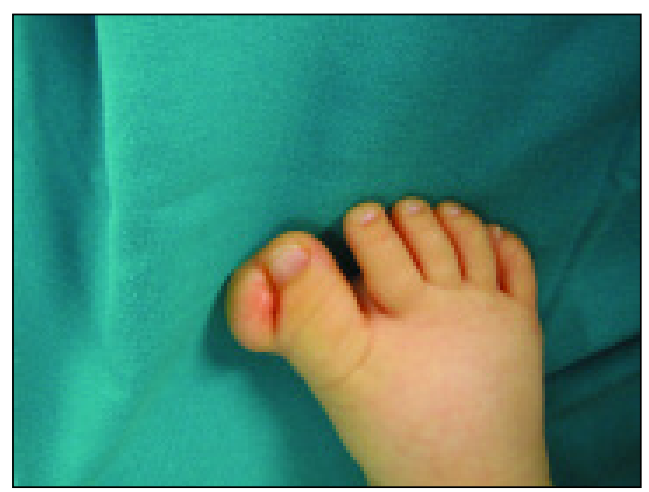

Figura 6. Duplicação de dedo - Polidactilia

\section{Sindactilia}

É uma malformação frequente, ocorrendo em $1 / 2.000 \mathrm{ou}$ 2.500 nascimentos, em que há junção de dois ou mais dedos. Há vários níveis de sindictalização, podendo ser parcial ou completa. Não causa problemas funcionais, sendo normalmente apenas um defeito estético. Os resultados da cirurgia nem sempre são satisfatórios, podendo, inclusivamente, ser piores do ponto de vista estético, pelo que, na maioria dos casos, o tratamento é desnecessário.

\section{Polidactilia}

A polidactilia (existência de dedos supranumerários) (Figura 6), é mais frequente no sexo feminino e existem numerosas formas, envolvendo não só as falanges, mas, também, os metatarsos. Pode causar problemas com o uso de calçado. O seu tratamento pode não ser tão simples como se pensa e deve ser bem planeado, sob pena de ter resultados insatisfatórios e, por vezes, irreparáveis. A razão do insucesso está ligada ao facto de, por vezes, estes doentes serem operados precocemente (antes do ano de idade), não permitindo ainda uma diferenciação cuidada dos tecidos patológicos, o que leva a recidivas frequentes.

\section{Microdactilia}

Podem estar associadas a outros problemas ortopédicos congénitos (por exemplo, malformação dos membros), pelo que deve ser feito o seu rastreio. $\mathrm{O}$ tratamento desta situação não é necessário.

\section{Macrodactilia}

Por vezes associada a outras situações, como a neuro- 


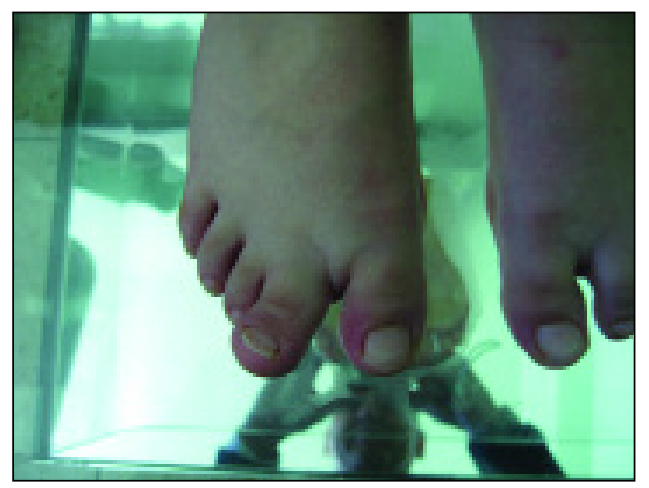

Figura 7. Macrodactilia

fibromatose ou acumulação de gordura, exige vigilância, pois em caso de crescimento rápido obriga a uma cirurgia. Por esse motivo as crianças devem ser vigiadas e referenciadas em caso de crescimento anormal. (Figura 7)

\section{Dedos flectidos}

Trata-se de uma entidade frequente na infância, em que há flexão e rotação dos dedos dos pés. O uso de fitas adesivas como tala tem sido recomendado, mas é desnecessário. Evolui, geralmente, para a cura espontânea.

\section{Cavalgamento de dedos}

Muito frequente nos $2^{\circ}, 3^{\circ} \mathrm{e} 4^{\circ}$ dedos, com evolução benigna para a cura. Pode ser bilateral. Tem carácter familiar; pode ser resultado de uma mutação genética. De uma maneira geral, o cavalgamento do $5^{\circ}$ dedo não responde às medidas conservadoras, como adesivos ou ortóteses e necessita, por vezes, de correcção cirúrgica, por poder causar dificuldades no uso de calçado. A sua referenciação deve ser ponderada com os pais, pois só se justifica se existir uma indicação ciúrgica.

\section{Dedo em martelo}

Os dedos em martelo são causados por deformidade em flexão da interfalângica proximal. O tratamento cirúrgico pode estar indicado na adolescência.

\section{Dedo em garra}

Estão associados ao pé cavo e problemas neurológicos. $\mathrm{O}$ tratamento faz parte dos procedimentos a efectuar na correcção desta patologia.

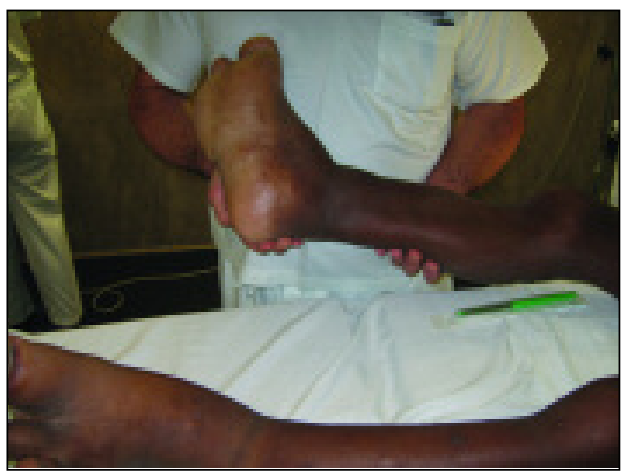

Figura 8. Síndrome de Proteus

\section{Hipertrofia}

A hipertrofia dos dedos está associada a síndrome de Proteus (Figura 8), neurofibromatose ou malformações vasculares. Pode envolver um ou mais dedos ou, até, todo o pé ou membro. O tratamento é complexo, difícil e pouco satisfatório.

\section{ATITUDE/PROCEDIMENTOS DO MÉDICO DE FAMÍLIA/PEDIATRA}

Como referido anteriormente, o pé infantil e a sua evolução constituem um dos principais motivos de preocupação por parte dos pais e de consulta de Ortopedia.

A anatomia da criança não é a mesma do adulto e este facto nem sempre foi reconhecido. Assim, as consultas de ortopedia para «correcção» do pé ou das pernas, tão populares nos últimos quarenta anos, tinham, na verdade, o objectivo de tornar os membros da criança iguais aos dos pais, o que viria a acontecer de qualquer modo, mesmo sem qualquer intervenção terapêutica.

Na presença de uma criança com uma deformidade do pé, uma história clínica cuidada, apoiada na história familiar, é fundamental. De facto, a grande maioria destas situações têm um cariz genético e, como tal, a história familiar pode ajudar a estabelecer o diagnóstico e a perceber a gravidade da deformidade - muitas vezes bem tolerada na idade adulta.

O exame objectivo é, também, essencial, pois, na maior parte das situações, permite o diagnóstico, sem necessidade de recorrer a exames auxiliares, como os radiológicos.

De salientar, ainda, que as deformidades congénitas dos pés podem estar associadas a outras malforma- 
ções, como a displasia de desenvolvimento da anca, pelo que estas crianças devem ser submetidas a um rastreio sistematizado de outras malformações.

Na avaliação da patologia do pé da criança, é necessário ter presentes os principais sinais de alarme. A identificação de uma deformidade rígida, que, com a manipulação, não assuma a posição anatómica, é sempre indicativa de uma situação patológica, requerendo uma observação ortopédica imediata. As deformidades assimétricas são, também, geralmente patológicas, requerendo igualmente uma avaliação ortopédica.

Uma situação benigna, o pé plano, merece aqui uma referência, pelas dúvidas que sempre levanta nos pais e que, por vezes, exigem uma observação ortopédica. O pé plano é normal na criança e o desenvolvimento da arcada plantar não depende do uso de calçado correctivo; todos os implantes, palmilhas ou reforços são inúteis e até, por vezes, prejudiciais. O pé plano deve ser encarado como um problema apenas se for rígido, doloroso ou muito pronunciado. Uma arcada plantar muito alta constitui, seguramente, um motivo muito maior de preocupação.

O calçado da criança deve ser flexível, confortável e nunca demasiado justo. Os sapatos duros devem ser evitados, pois impedem o movimento normal do pé, que é essencial para o desenvolvimento da força muscular. A sola não deve ser muito escorregadia nem demasiado aderente, pois é uma fonte frequente de que- das. O material de que é feito o sapato deve ser poroso e permitir a respiração, ter características térmicas e de protecção adequadas e permitir liberdade de movimentos.

Devemos ter a noção de que a marcha se desenvolve e aperfeiçoa com o crescimento até aos 6-7 anos, idade em que a criança adquire um padrão de marcha semelhante ao dos adultos.

\section{REFERÊNCIAS BIBLIOGRÁFICAS}

1. Herring J, editor. Tachdjian's Pediatric Orthopaedics. 4th ed. Philadelphia:W.B. Saunders; 2008.

2. Staheli LT, editor. Practice of Pediatric Orthopedics. Philadelphia: Lippincott, Williams \& Wilkins; 2001.

3. Ponseti IV, Campos J. Observations on pathogenesis and treatment of congenital clubfoot. Clin Orthop Relat Res 1972 May; 84: 50-60.

4. Wenger DR, Mauldin D, Speck G, Morgan D, Lieber RL. Corrective shoes and inserts as treatment for flexible flatfoot in infants and children. J Bone Joint Surg Am 1989 Jul; 71 (6): 800-10.

5. Mubarak SJ, Patel PN, Upasani VV, Moor MA, Wenger DR. Calcaneonavicular coalition: treatment by excision and fat graft. J Pediatr Orthop 2009 Jul-Aug; 29 (5): 418-26.

Os autores declararam não possuir conflitos de interesses

\section{ENDEREÇO PARA CORRESPONDÊNCIA}

Francisco Sant'Anna

Serviço de Ortopedia, Hospital Dona Estefânia

Rua Jacinta Marto, 1169 Lisboa, Portugal

E-mail: fccsantanna@gmail.com

\section{ABSTRACT}

\section{JUVENILE FOOT DEFORMITIES}

A child's feet are a major source of concern for the parents of children undergoing physical development. In this article, the authors approach the main deformities observed at birth and during development, as well as the therapeutically indications. Additionally, guidelines for the treatment of these deformities are presented to the general practitioner or paediatrician.

Keywords: Child; Foot; Foot Deformity; Flatfoot; Clubfoot. 